\title{
EXPERIENCE WITH SHIPBORNE MEASUREMENTS OF SURFACE CURRENT FIELDS BY HF RADAR
}

\author{
By Klaus-Werner Gurgel
}

\section{There are several \\ difficulties to be \\ solved for successful \\ measurements of \\ surface current fields}

from a slowly sailing

ship ... .
$\mathrm{O}$ U CEANOGRAPHIC RESEARCH using HF radar techniques started in Germany in 1980 by adopting NOAA's CODAR (Coastal Ocean Dynamics Applications Radar), which has originally been introduced by Barrick et al. in 1977. In Germany, the CODAR has been modified and used during several experiments since 1981. From 1985 to 1992, the University of Hamburg CODAR has been extended for shipborne operation. The first experiment has been carried out on board the German icebreaker Polarstern, which most of the time has been sailing within the ice, far away from open water. The main result of this experiment was that the attenuation of ice-covered sea reduces the performance and working range extremely. Good measurements have only been possible with the ship sailing at the ice edge or in open water. However, this application did not need an icebreaker, so the following experiments have been carried out using the University of Hamburg $R N$ Valdivia.

The intention for operating the CODAR onboard a ship was to enable the measurement of surface current fields in front of the rough Norwegian coast, where the combination of a land-based and a shipborne CODAR has been used during the NORCSEX' 88 experiment (Essen et al., 1989), and on the open sea at the ice edge and at the Arctic Front. There are several difficulties to be solved for successful measurements of surface current fields from a slowly sailing ship, which will be discussed in the following sections. Finally. some results of a measurement campaign at the Arctic Front are shown. A more complete discussion of the shipborne CODAR can be found in Gurgel (1993) and Gurgel (1994).

\section{Difficulties in Operating a Shipborne HF Radar}

During several experiments using three different ships, some main difficulties have been identified:

Klaus-Werner Gurgel, Universität Hamburg, Institut für Meereskunde, Troplowitzstrasse 7, D-22529 Hamburg, Germany. Email: gurgel@ifm.uni-hamburg.de
- to measure speed and direction of the ship and keep it as constant as possible;

- to compensate the influence of the ship on the antenna array; and

- to filter out the additional phase modulation of the sea echoes due to the pitch and roll motion of the ship.

The Global Positioning System (GPS) has been used for navigation. In near shore areas, other systems show acceptable accuracy and can also be used. The other difficulties are described in the following sections.

Antenna Arrangement to Minimize the Distortion of the Antenna Pattern

The first problem when setting up a HF radar onboard a ship is to find an appropriate location for the antenna systems. In contrast to the landbased radar, there is a severe interaction between the ship's body and the receiving antenna array, which still must be usable to find the direction of the sea echoes. Similar to the land-based system, the receiving antenna is a four-element array of vertical polarized $\lambda / 4$ ground planes arranged in a square as described in Weber and Leise (1982). The arrangement of antennas finally selected can be seen in Figure 1.

The amplitude characteristics and phase differences of the four antennas are calibrated in the ship's environment before starting a measurement campaign. This is done by transmitting a constant signal from the coast and receiving it at the ship about 5 nautical miles away. To find the incident angle of a sea echo, a least-squares-fit of the measured phase differences to the calibration values is used.

Although the calibration values are used in finding the incident angle, in the presence of superposed gaussian noise on the sea echo's phase differences, a non-gaussian distribution of resolved incident angles can be observed. The average angle, therefore, can be distorted by an offset, which increases with growing noise due to pitch and roll motions or decreasing strength of the sea echoes. 


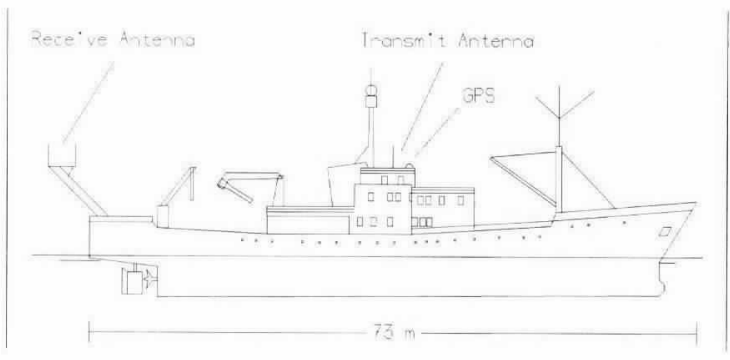

Fig. 1: The arrangement of antennas on $R / V$ Valdivia.

\section{Ship's Pitch and Roll Movement}

Another difficulty in analyzing the backscattered sea echoes is the ship's pitch and roll movement causing the sea echoes to be superposed by amplitude and phase modulation. Amplitude modulation is due to rotating the antenna out of the vertical polarization and changing the antenna's coupling to the sea surface; phase modulation is caused by changing the distance from the scattering area to the antenna. It turned out that phase modulation is the major effect.

A filter algorithm has been developed to separate this modulation from the sea echoes, which works well to $-10 \mathrm{~dB}$ modulation strength. A high roll frequency of the ship will be an advantage in this context. As the ship's movement is a function of the sea state and the sea state a function of wind speed, $-10 \mathrm{~dB}$ modulation strength will be exceeded at wind speeds above $19 \mathrm{~m} \mathrm{~s}^{-1}$ for $R / V$ Valdivia.

\section{Hints on Operation of a HF Radar Onboard a Ship}

- A big and heavy ship has the advantage of weak pitch and roll movements, reducing modulation effects.

- If only a smaller ship is available, it should roll at a frequency higher than $0.12 \mathrm{~Hz}$ to get the modulation products as far away from the sea echoes as possible.

- The ship should run at the lowest speed possible to sail a constant course. Because of errors in the direction finding algorithm for the sea echoes, the ship's speed may be compensated by a wrong value.

- The ship's speed must be $<3 \mathrm{kt}$ to resolve current velocities up to $1 \mathrm{~m} \mathrm{~s}^{-1}$.

- Installing the receiving antenna low above the sea reduces phase modulation due to pitch and roll movements, but the distortion of the antenna pattern may increase because of a nearer distance to the ship's body.

\section{System Accuracy}

If the above requirements are met, an accuracy of $2-5 \mathrm{~cm} \mathrm{~s}^{-1}$ for the radial component of the current velocity and an azimuthal resolution of $3^{\circ} \mathrm{can}$ be achieved. These values can be calculated from the statistics of the data. A practical working range at a radar frequency of $29.85 \mathrm{MHz}$ is $45-50 \mathrm{~km}$, when integrating the sea echoes over an 18-min time interval. These characteristics are valid up to sea states at $19 \mathrm{~m} \mathrm{~s}^{-1}$ windspeed for $R / V$ Valdivia and using GPS without Selective Availability (SA) activated for correction of the ship's speed. SA has been introduced to degrade the accuracy of GPS available to nonmilitary users.

\section{Surface Currents at the Arctic Front}

The shipborne CODAR has been used during several cruises to the Arctic Front above Mohn's Ridge near Svalboard. The Arctic Front is originated by the West Svalboard Current carrying warm and salty North Atlantic water to the north and recirculation of cold and less salty Arctic water carried by the East Greenland Current to the south. Eddies at 10-20 km diameter and current speeds up to $50 \mathrm{~cm} \mathrm{~s}^{-1}$ can be observed.

\section{HF Radar Measurements}

Because there was only one ship available during the campaign in August 1989, the ship had to be moved to different positions to obtain the measurements of radial components of the surface current field from different angles. Additionally, the GPS navigation had been available for some hours a day only, so scanning the complete area took one and a half day. Fortunately, SA had not been activated at that time, so GPS accuracy was sufficient without additional equipment.

Under these conditions, it must be assumed that the surface current field is stable over one and a half day. Because the windspeed kept changing during this time, the wind-driven part of the surface current was estimated to be

$$
\vec{V}_{0}=0.018 \cdot\left|\begin{array}{rr}
\cos \left(-15^{\circ}\right) & -\sin \left(-15^{\circ}\right) \\
\sin \left(-15^{\circ}\right) & \cos \left(-15^{\circ}\right)
\end{array}\right| \cdot \vec{W}
$$

and subtracted from each measurement of radial components before calculating the two-dimensional current field. The ratio $\left|\vec{V}_{0}\right| /|\vec{W}| \approx 0.018$ and angle $\approx 15^{\circ}$ have been published by Essen (1992). The result can be seen in Figure 2a.

\section{Current Field Calculated From CTD and XBT Data}

Standard oceanographic equipment has been used on $R / V$ Valdivia parallel to the HF radar, which includes a temperature/salinity sensor mounted at the ship, $4 \mathrm{~m}$ below the sea surface, CTD (Conductivity Temperature Depth) and XBT (eXpendable Bathy Thermograph) sondes.

To get a fast overview, the area has been scanned by the temperature/salinity sensor and XBTs. Only a few CTD measurements were taken at that time. After knowing the location of the Arctic Front from the temperature signal, the CTD measurements were intensified and the density field at the front has been measured.

\section{A big and heavy}

ship has the

advantage of weak

pitch and roll

movements . . 

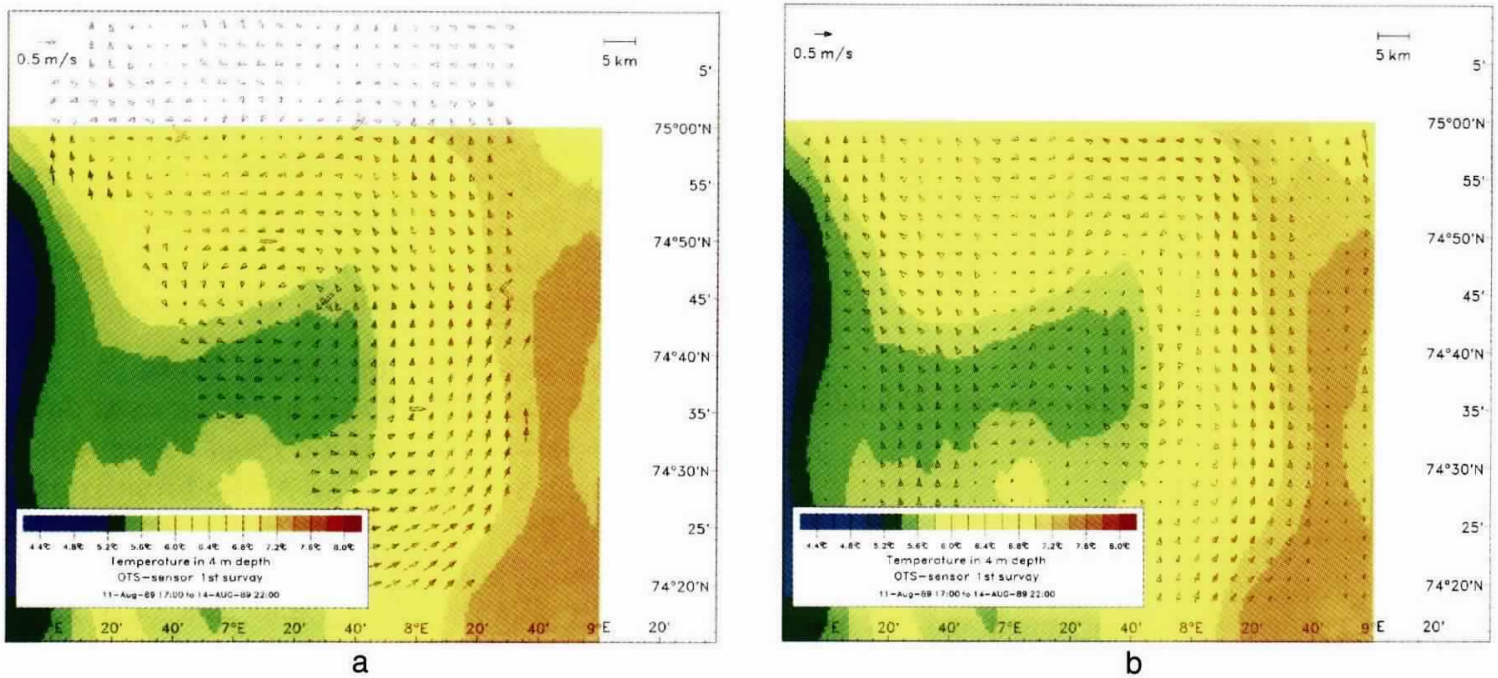

Fig. 2: (a) Surface current field calculated from 10 measurements of radial components taken by the shipborne HF radar at different positions and courses between 15 AUG 1989 17:08 UT and 17 AUG 1989 09:41 UT. The varying winddriven part of the surface current has been removed. (b) Surface Current field calculated from the three-dimensional density field, derived from CTD and XBT measurements between 11 AUG 1989 17:00 UT and 14 AUG 1989 22:00 UT.

Because the fast survey gives a more synoptic approach, which can better be compared with the HF radar measurements, a typical temperaturesalinity correlation has been derived from all CTD data and was then used for the XBT data to add a typical salinity profile. By this way, all XBT and CTD measurements during the fast survey could be used to calculate geostrophical currents at the sea surface. The result can be seen in Figure $2 b$.

When subtracting the varying wind-driven part from the radial components of the current fields as measured by HF radar, a good agreement with the geostrophical current field can be found within the calculated accuracy of the HF radar measurements. The main current structure of the Arctic Front can be seen in both figures. Additionally, one has to keep in mind that there is a time lag of some days between the two current fields, that the density field has been modeled using a typical temperature-salinity correlation, and that none of the current fields shows a real synoptic approach.

\section{Conclusion}

HF radars can successfully be operated onboard a ship as long as the weather conditions do not cause the ship to roll and pitch too heavily. $R / V$ Valdivia can be used up to sea states generated by $19 \mathrm{~m} \mathrm{~s}^{-1}$ wind speed. To compensate the ship's movement during operation of the HF radar, GPS can be used, as long as SA can be removed from the satellite data, which can be done by Differential GPS or by using state-of-the-art receivers. Because one radar measures only the radial component of the surface current field, ei- ther a second radar must be used, or, if the currents are stable over some hours, the ship can be moved to get measurements from different directions. Measured surface current fields at the Arctic Front have shown good agreement with conventional methods using CTD and XBT data.

\section{Acknowledgments}

This work was supported by the German Research Foundation (DFG) in the Sonderforschungsbereich 318, Klimarelevante Prozesse im System Ozean-Atmosphäre-Kryosphäre. The author thanks the members of the German CODAR group, H.H. Essen, T. Schlick, F. Schirmer, and our technician M. Hamann for supporting the experiments; the scientific crew of $R / V$ Valdivia for taking the CTD and XBT measurements; and the ship's crew for sailing the difficult CODAR courses.

\section{References}

Barrick, D.E., M.W. Evans and B.L. Weber, 1977: Ocean surface current mapped by radar. Science, 198, 138-144.

Essen, H.H., K.W. Gurgel, F. Schirmer and T. Schlick, 1989: Surface currents during NORCSEX ' 88 , as measured by a land- and a ship-based HF-radar. Proc. IGARSS'89, Vol. 2, 730-733.

Gurgel, K.-W., 1993: Flächenhafte Messung der Oberflächenströmung vom fahrenden Schiff aus. Ph.D. thesis, Universität Hamburg.

1994: Shipborne Measurement of Surface Current Fields by HF Radar. L'onde Electrique, 74, No. 5, 54-59.

Weber, B.L. and J.A. Leise, 1982: A four-element direction finding antenna. NOAA Tech. Memo., ERL WPL-99, U.S. Dept. Commerce, NOAA/ERL, Boulder, CO. 